\title{
Environment and Sustainable Development in the Kingdom of Saudi Arabia: Current Status and Future Strategy
}

\author{
Tahir Husain ${ }^{1} \&$ Ahmed Abdulwahab Khalil ${ }^{2}$ \\ ${ }^{1}$ Faculty of Engineering and Applied Science, Memorial University of Newfoundland, St. John's, Canada \\ ${ }^{2}$ Vice Presidency for Projects, Sustainability Department, King Abdulaziz University, Jeddah, Saudi Arabia \\ Correspondence: Tahir Husain, Faculty of Engineering and Applied Science, Memorial University of \\ Newfoundland, St. John's, A1B3X5 NL, Canada. Tel: 1-709-864-8781. E-mail: thusain@mun.ca
}

Received: August 13, $2013 \quad$ Accepted: October 16, $2013 \quad$ Online Published: November 6, 2013
doi:10.5539/jsd.v6n12p14

\begin{abstract}
Air quality deterioration in urban areas; high energy demand and consumption due to regional population growth and economic development; concerns about safe drinking water supplies due to a scarcity of fresh water; air quality deterioration, industrial pollution, waste management, and pollution in coastal areas; and subsequent stress on marine ecosystems are all major environmental challenges being faced by the Kingdom of Saudi Arabia. For effective protection of the environment, an interdisciplinary approach within a sustainable framework, which integrates human needs with economic development and environmental protection, is required. This paper presents an overview of Saudi Arabia's major environmental problems and challenges and offers opportunities to use economic growth, social equity, and protection of the environment as interrelated components. The role of active participation by governments, stakeholders, businesses, academic institutions, and individuals in the decision-making process and an inter-disciplinary research approach will be identified for each major environmental issue.
\end{abstract}

Keywords: air quality, energy, Saudi Arabia, sustainable development, waste management, water supply

\section{Introduction}

The interconnections between economic growth and the environment were recognized in the 1972 United Nations Stockholm Conference on the Human Environment. Fifteen years later, during the World Commission on Environment and Development, the UN-sponsored Brundtland Commission released Our Common Future, a report that captured widespread concerns about the environment and poverty in many parts of the world. This report indicated that economic development cannot stop but must change its course to fit within the planet's ecological limits. It also popularized the term "sustainable development", defining it as "development that meets the needs of the present without compromising the ability of the future generations to meet their needs". During the World Commission, an agenda for environment and development in the 21st Century known as Agenda 21 was adopted and recognizes each nation's right to pursue social and economic progress. The lifestyle of the current civilization was addressed in Principle 8 of the Rio Declaration. Agenda 21 further reaffirmed that sustainable development is the integration of economic, social, and environmental pillars. It also calls on countries to adopt national strategies for sustainable development (NSDS) that build upon and harmonize various local economic, social, and environmental policies and plans within each country. In 2002, the World Summit on Sustainable Development (WSSD) was convened in Johannesburg to renew a global commitment to sustainable development. It urged the United States not only to take immediate steps to formulate and elaborate national strategies for sustainable development but also to begin their implementation by 2005 .

The Kingdom of Saudi Arabia is committed to effectively implementing sustainable development within its national development plan and has made steady progress in its socio-economic development, gender equity, standard of living, health, education, and environmental legislation. Some of the potential areas in the Kingdom of Saudi Arabia where environmental sustainability research can play important roles include:

(1) National air quality management plan

(2) Sustainable water resources planning

(3) Sustainable energy planning 
(4) Marine pollution and ecological impact

(5) Waste management

Many other environmental issues exist which are not listed here. This paper, however, emphasizes an overview of the current status of the above major environmental concerns and offers a future strategy for how a sustainability concept can be applied effectively.

\section{National Air Quality Management Plan}

Air quality is a major public health and environmental issue that poses a significant threat to human health and the environment. Air pollutants increase the risk of respiratory tract infections, affect cardiac and pulmonary systems, lead to allergies, affect asthmatics, and may act as cancer precursors. Acute respiratory disease is responsible for some 4 million deaths a year of children under the age of five in developing countries. Increased levels of inhalable particulates and gaseous pollutants seriously affect people with respiratory and cardiovascular diseases. The adverse health and environmental effects of air pollution are particularly apparent in major cities, where the problems of population growth, industrialization, ever-increasing motor-vehicle use, and unsustainable development are concentrated.

\subsection{Current Status}

A baseline study conducted on the status of air quality in the Kingdom of Saudi Arabia shows elevated levels of oxides of nitrogen $\left(\mathrm{NO}_{\mathrm{x}}\right)$, ozone $\left(\mathrm{O}_{3}\right)$, and inhalable particulates $\left(\mathrm{PM}_{10}\right)$ in such major cities as Jeddah, Riyadh, and Dhahran. Petroleum sectors, consisting of refineries, terminals, and gas/oil separation plants (GOSPs), are major sources of volatile organic compounds (VOCs), sulfur dioxide $\left(\mathrm{SO}_{2}\right)$, and $\mathrm{NO}_{\mathrm{x}}$. Power and desalination plants contribute significantly to Saudi Arabia's air pollution load due to its use of heavy fuel oil with high sulfur content. Many major cities have high levels of $\mathrm{O}_{3}$, which must be reduced by good strategic planning. VOCs combined with high levels of $\mathrm{NO}_{\mathrm{x}}$ and sunlight are major contributors to $\mathrm{O}_{3}$ increase in urban areas. A detailed investigation of the formation of $\mathrm{O}_{3}$ and smog in major cities is required; it should use a monitoring and modeling approach linked with a quantitative risk assessment because of the adverse health impact of $\mathrm{O}_{3}$ combined with $\mathrm{SO}_{2}$, fine particulates, $\mathrm{NO}_{\mathrm{x}}$, and VOCs.

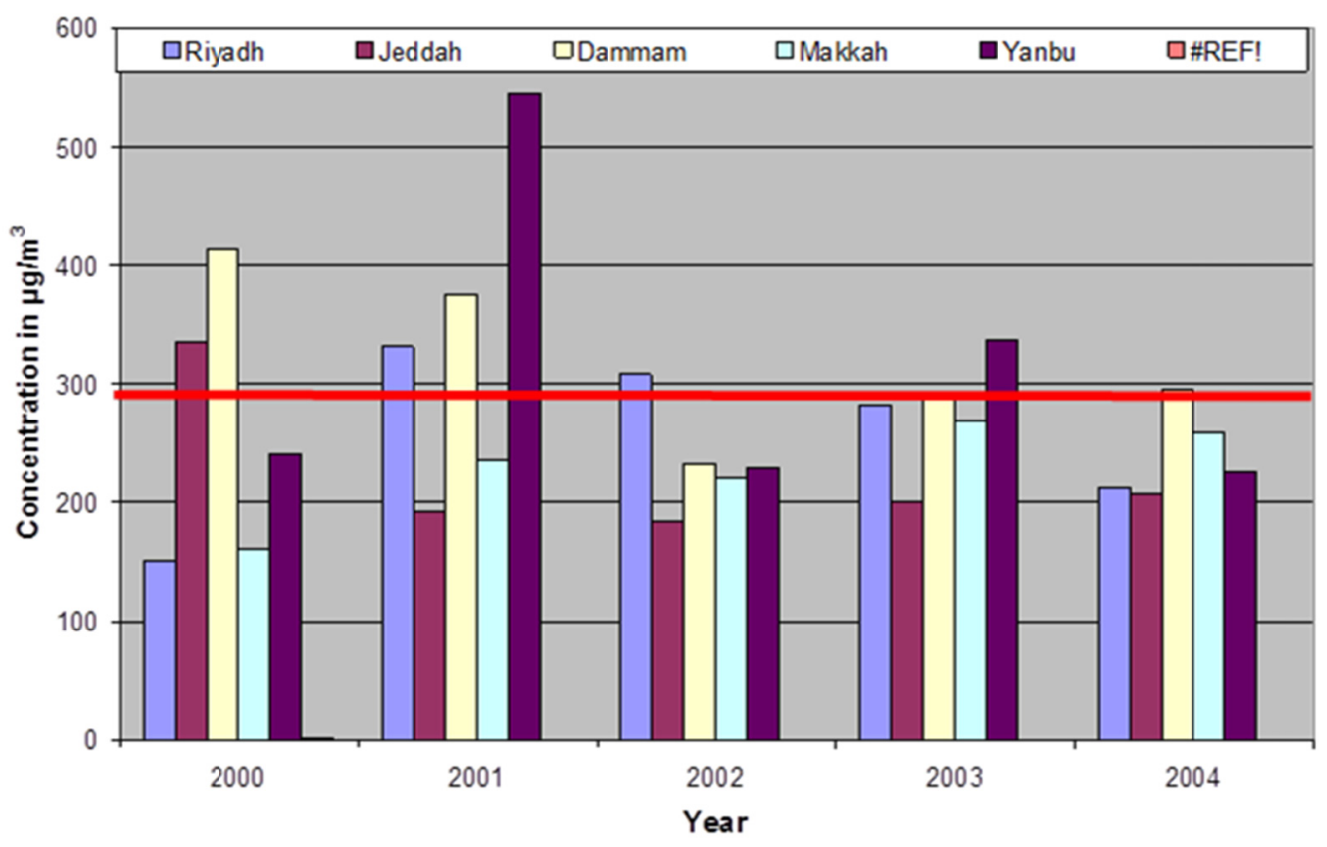

Figure 1a. Ambient ozone concentration trend in major Saudi Arabian cities 


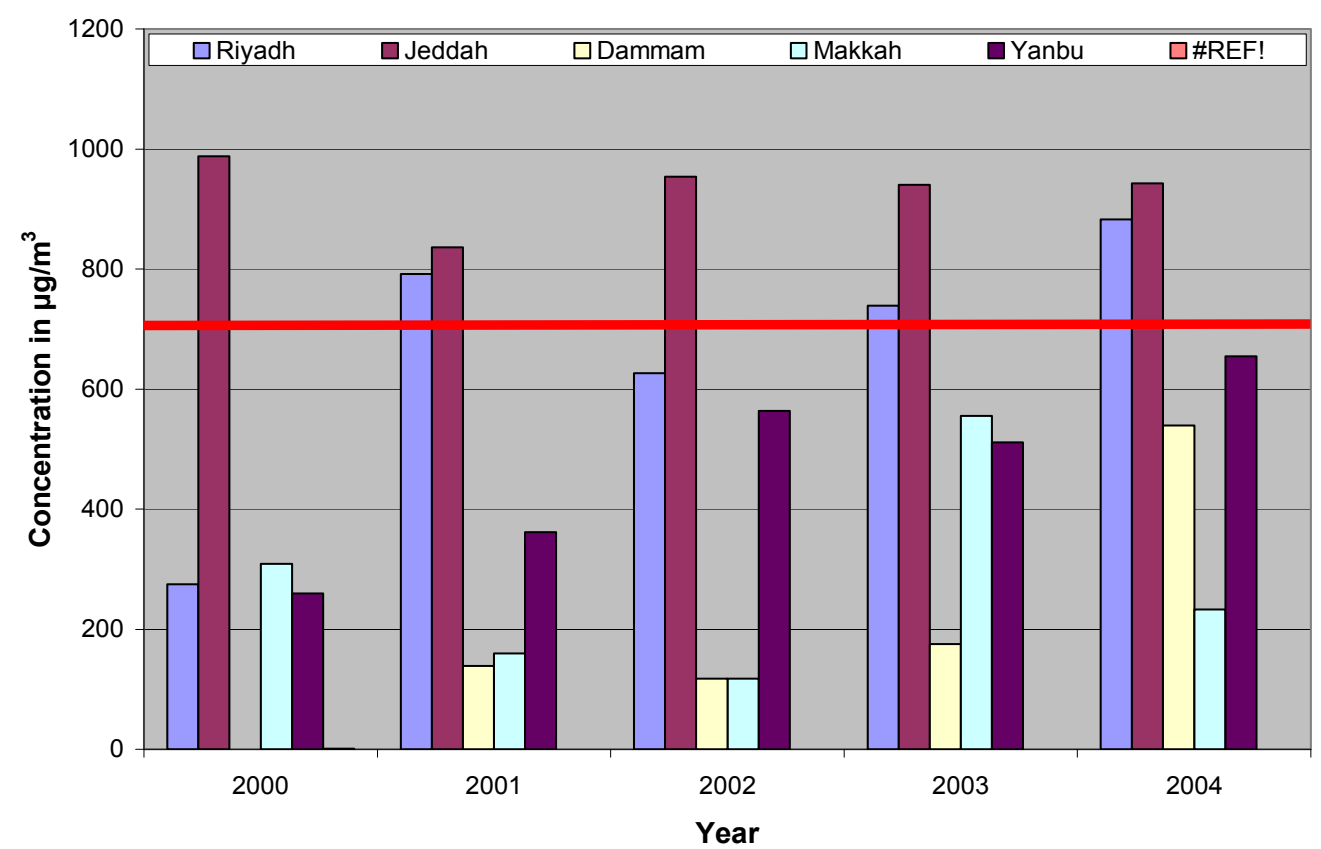

Figure1b. Ambient sulfur dioxide concentration trend in major Saudi Arabian cities

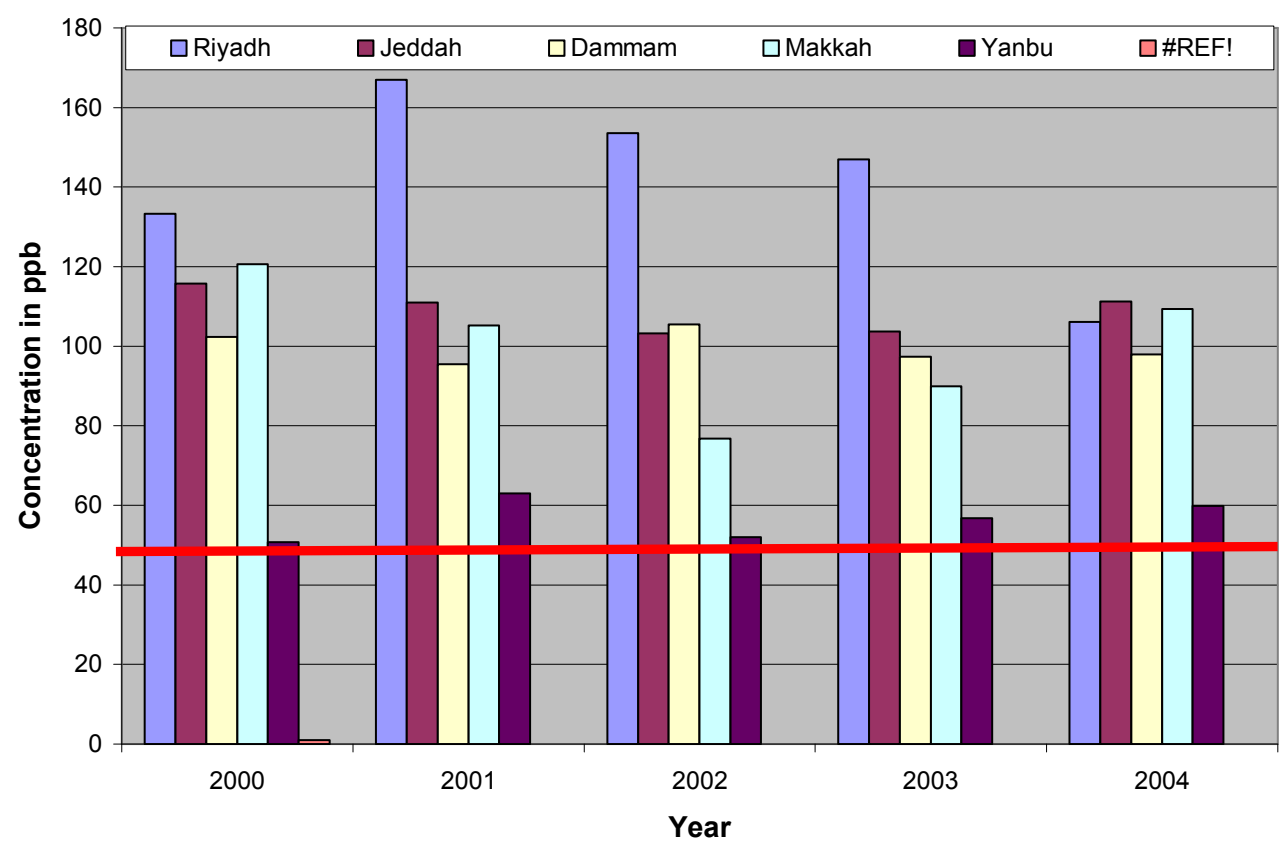

Figure 1c. Ambient oxides of nitrogen concentration trend in major Saudi Arabian cities 


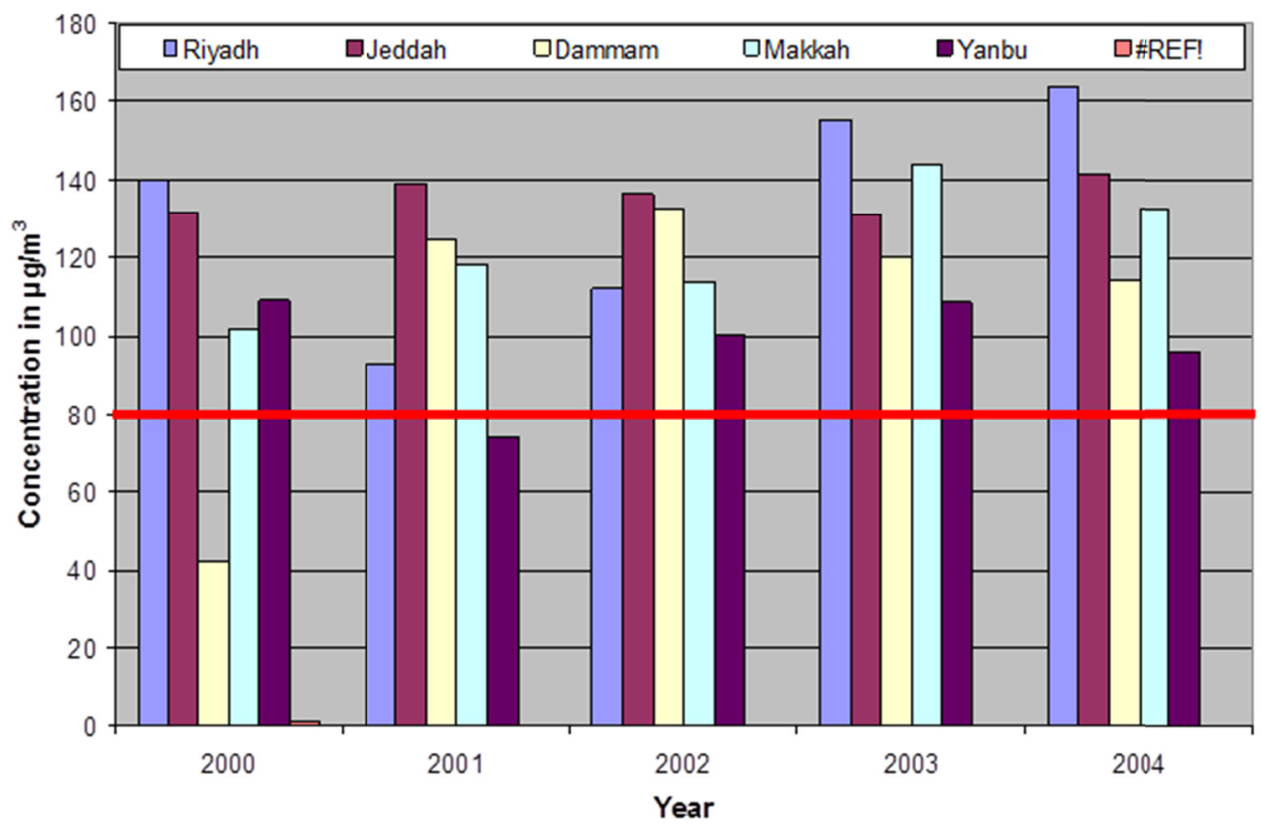

Figure 1d. Inhalable particulate concentration trend in major Saudi Arabian cities

\subsection{Future Strategy}

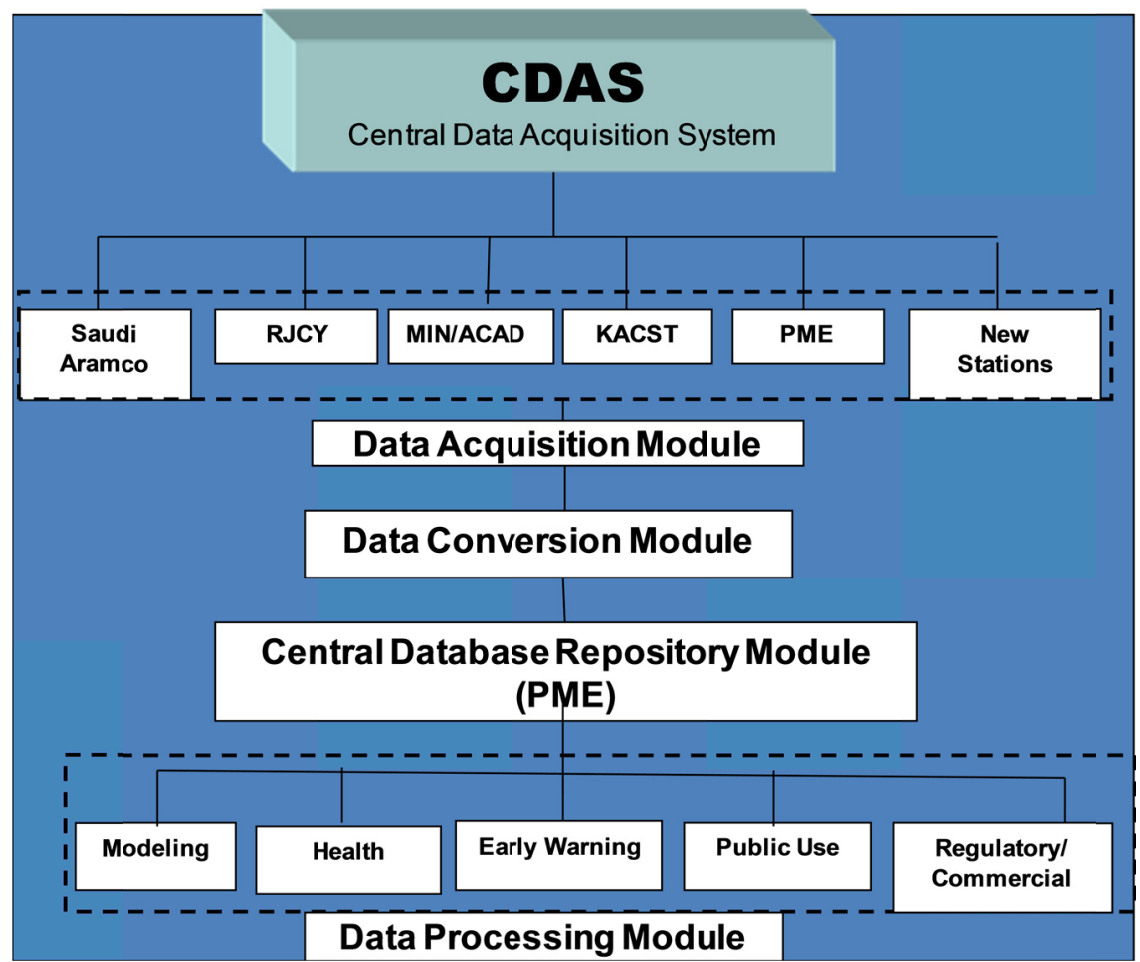

Figure 2. National air quality database

A sustainable national plan is needed for air quality management and assessment; it would integrate monitoring, modeling, and database tools, which include research on emission monitoring, database development, and dispersion modeling for stationary and mobile sources; the development of cost-effective emerging monitoring technologies; research on environmental and health risk assessment and risk management; and an estimation of the impact of abatement alternatives using multi-criteria decision-making (MCDM) tools. National programs in 
monitoring, assessment, and control are implemented by PME. An air monitoring network is being expanded, with more than 100 new air quality stations being installed in cities and towns (Mofarrah \& Husain, 2010; Mofarrah et al., 2011). Several other organizations in the Kingdom also collect data on air quality, for example, Saudi Aramco's Air Quality Monitoring \& Meteorology Network (AMMNET), the Royal Commission for Jubail and Yanbu (RCJY) network in the industrial cities of Jubail and Yanbu, and the King Abdulaziz City for Science and Technology (KACST) air quality network in Riyadh. In order to use this data effectively, it is proposed that all air quality and meteorological data be integrated into a central data repository as a national database. Such integration will assist model validation, impact and risk assessment studies, and regulatory uses. It will require a compatibility evaluation of the hardware and software and the development of a relational database with user-friendly menu-driven modules (Figure 2).

For the effectiveness of sustainable air quality management at a national level, it is important to integrate monitoring, modeling, and databases through decision support software; keeping a balance between sustainable economic development and protection of human health and ecosystems requires the active participation of stakeholders. During the process of developing these tools, the capacity building and training of highly skilled professionals is essential. The interactions of all of the above elements are shown schematically in Figure 3.

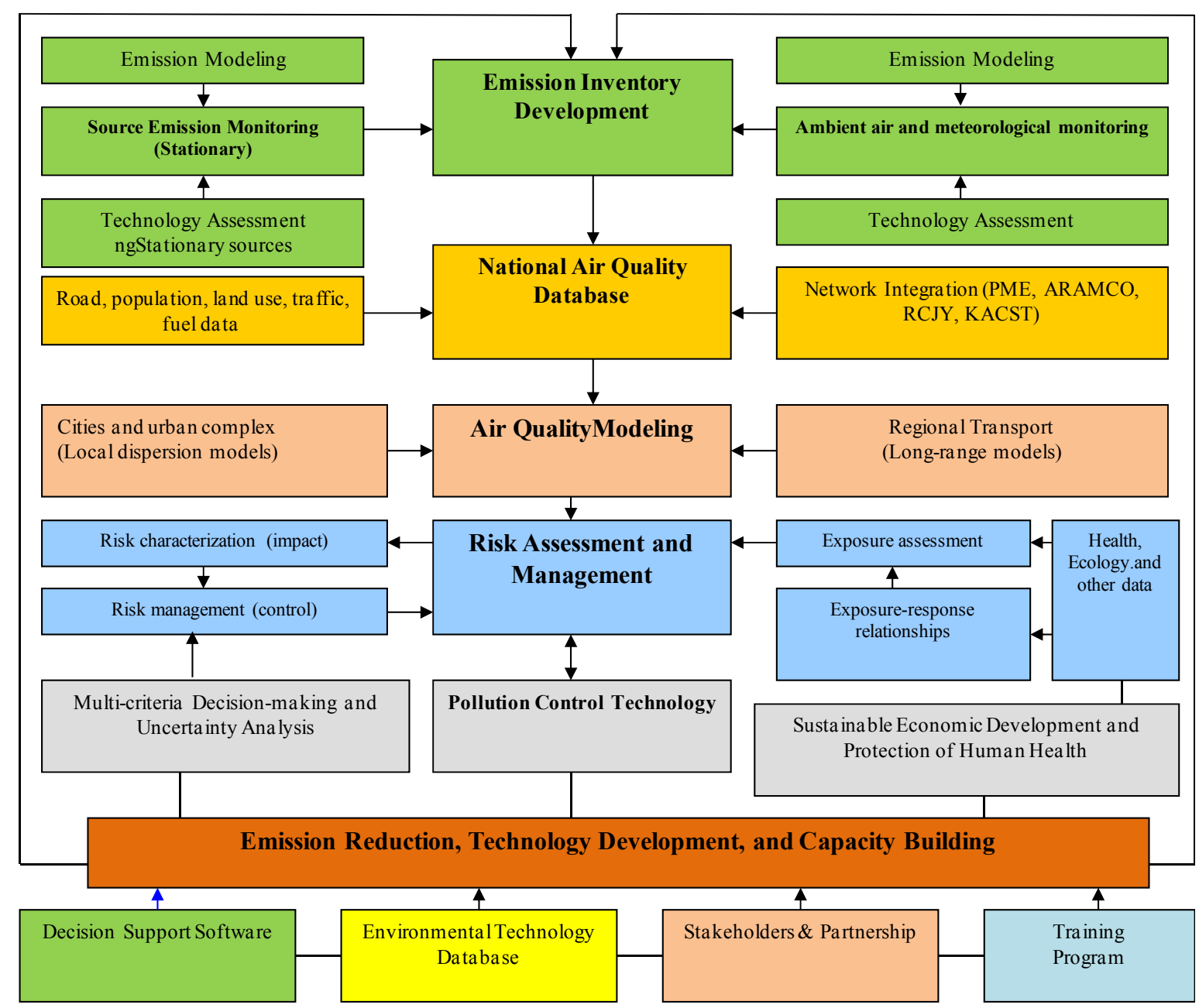

Figure 3. Elements of a sustainable air quality management plan

\section{Sustainable Water Resources Planning}

Sustainable water resources planning (SWRP) is based on the proper integration of social, environmental, and technical aspects by recognizing water source and water quality linkages, predicting water demands, and incorporating conflicting objectives and uncertainty into the data and model parameters using multi-objective optimization tools and probabilistic models. SWRP also integrates economic, engineering, technological, and 
social attributes in a multi-objective framework and develops effective awareness and communication among various stakeholders.

SWRP has become a crucial tool in the development of areas where renewable freshwater resources are highly constrained (Husain, 2009). To meet an increasing demand for water, many countries are developing alternative sources, including desalination as a potable source and treated wastewater effluent for landscaping, restricted irrigation, and aquifer recharge (Husain \& Ahmed, 1997). Under climate-change conditions, even temperate regions face certain risks of droughts, and occasional extreme flooding causes serious damage. To address these major challenges, the prediction of both the whole hydrologic regime with high resolution and the long-term environmental consequences resulting from changes in that regime is needed. SWRP, a tool to evaluate and find viable options in an environmentally sound and cost-effective manner, integrates contributions from natural, social, scientific, and engineering disciplines in order to derive potential practical measures. SWRP is also compatible with other societal goals (e.g., protecting biodiversity, climate change, making good use of water for agriculture, and flood protection).

\subsection{Current Status}

The depletion of water in aquifers due to increased agricultural and landscaping activities in Saudi Arabia has exerted pressure on natural water systems, including renewable and non-renewable water resources. Approximately 22 billion cubic meters of water was used in Saudi Arabia in 2005 for which non-renewable groundwater was a major source, while surface and renewable groundwater shared $36 \%$ of the demand, desalination $5 \%$, and treated reclaimed wastewater only $1 \%$ of the total demand. In its current Five-Year Development Plan, the Kingdom of Saudi Arabia emphasizes the use of treated wastewater effluent and its integration with other alternatives in developing a national water plan. In Saudi Arabia, a significant amount of water is used for agricultural and landscaping purposes (Table 1), from non-renewable groundwater sources (Al-Humoud et al., 2003). Domestic and industrial water requirements are $45 \%$ and $8 \%$ of the total demand respectively; consequently, through proper allocation, a significant percentage of the agricultural and landscaping needs could be met by the use of treated domestic and industrial wastewater. As such, the extraction of fresh water from non-renewable sources could be greatly reduced and wastewater disposal minimized by the same amount; this would translate to a reduction of other environmental problems. However, $1 \%$ of the total demand is currently being satisfied by the use of treated wastewater (Shareef et al., 2005). A supply and demand schematic is presented in Figure 4.

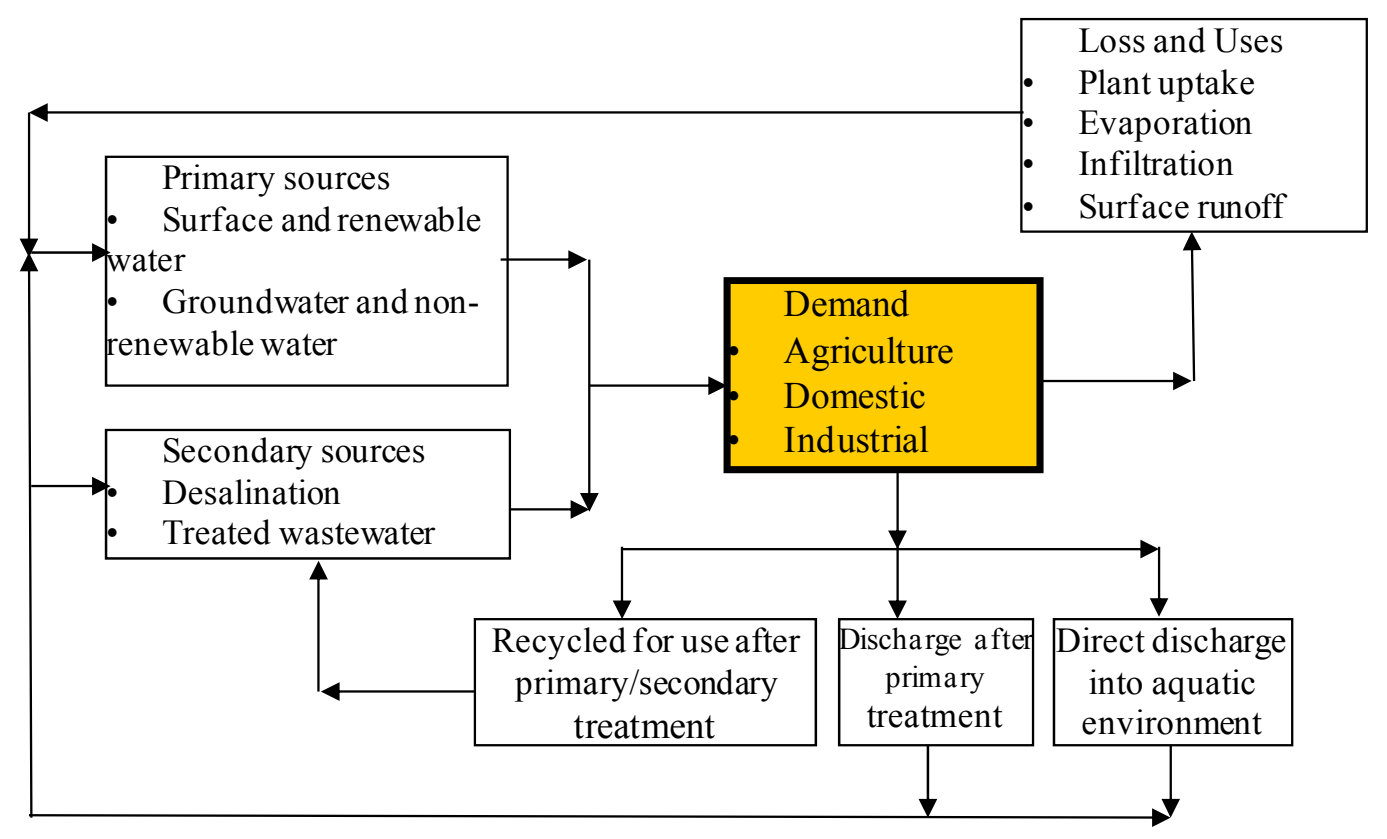

Figure 4. Schematic for water supply and demand in Saudi Arabia 
Table 1. Water demands in MCMY in Saudi Arabia and projection for 2030 (MCMY = million cubic meters per year)

\begin{tabular}{cccc}
\hline Sector & $\mathbf{2 0 0 0}$ & $\mathbf{2 0 0 5}$ & Projected for 2030 \\
\hline Domestic & 9,340 & 10,116 & 14,415 \\
Industrial & 1,660 & 1,799 & 2,560 \\
Agricultural & 9,740 & 10,565 & 15,059 \\
Total & $\mathbf{2 0 , 7 4 0}$ & $\mathbf{2 2 , 4 8 0}$ & $\mathbf{3 2 , 0 3 4}$ \\
\hline
\end{tabular}

Table 2. Possible future integration with treated wastewater (MCMY = million cubic meters per year)

\begin{tabular}{|c|c|c|c|c|c|}
\hline & \multirow{2}{*}{$\begin{array}{l}\text { Current supply } \\
\text { MCMY (\%) }\end{array}$} & \multicolumn{4}{|c|}{ Projection for 2030 and supplies in MCMY (\%) } \\
\hline & & Case I & Case II & Case III & Case IV \\
\hline $\begin{array}{l}\text { Non-renewable / } \\
\text { groundwater sources }\end{array}$ & $\begin{array}{c}13,120 \\
(58.4 \%)\end{array}$ & $\begin{array}{c}19,326 \\
(60.3 \%)\end{array}$ & $\begin{array}{l}14,529 \\
(45.3 \%)\end{array}$ & $\begin{array}{l}12,919 \\
(40.3 \%)\end{array}$ & $\begin{array}{l}10,571 \\
(33 \%)\end{array}$ \\
\hline $\begin{array}{l}\text { Surface / renewable } \\
\text { sources }\end{array}$ & $\begin{array}{c}8,000 \\
(35.6 \%)\end{array}$ & $\begin{array}{l}8,000 \\
(25 \%)\end{array}$ & $\begin{array}{l}8,000 \\
(25 \%)\end{array}$ & $\begin{array}{l}8,000 \\
(25 \%)\end{array}$ & $\begin{array}{l}8,000 \\
(25 \%)\end{array}$ \\
\hline Desalination water & $\begin{array}{l}1,050 \\
(4.7 \%)\end{array}$ & $\begin{array}{l}1,505 \\
(4.7 \%)\end{array}$ & $\begin{array}{l}1505 \\
(4.7 \%)\end{array}$ & $\begin{array}{l}1505 \\
(4.7 \%)\end{array}$ & $\begin{array}{l}641 \\
(2 \%)\end{array}$ \\
\hline $\begin{array}{l}\text { Treated domestic } \\
\text { wastewater }\end{array}$ & $\begin{array}{c}310 \\
(1.3 \%)\end{array}$ & $\begin{array}{l}3,203 \\
(10 \%)\end{array}$ & $\begin{array}{l}8,000 \\
(25 \%)\end{array}$ & $\begin{array}{l}9,610 \\
(30 \%)\end{array}$ & $\begin{array}{l}11,212 \\
(35 \%)\end{array}$ \\
\hline $\begin{array}{l}\text { Treated industrial } \\
\text { wastewater }\end{array}$ & $\begin{array}{c}0 \\
(0 \%)\end{array}$ & $\begin{array}{c}0 \\
(0 \%)\end{array}$ & $\begin{array}{l}0 \\
(0 \%)\end{array}$ & $\begin{array}{l}0 \\
(0 \%)\end{array}$ & $\begin{array}{l}1,602 \\
(5 \%)\end{array}$ \\
\hline Total demand (MCMY) & 22,480 & 32,034 & 32,034 & 32,034 & 32,034 \\
\hline
\end{tabular}

Future water demands can be satisfied by using surface and renewable sources, groundwater and non-renewable sources, desalinated seawater, and treated wastewater. To meet these challenges, four options using varying amounts of treated wastewater $(10 \%, 25 \%, 30 \%, 35 \%)$ in combination with groundwater and desalinated water sources are developed, as listed in Table 2. The fourth option in the table represents a reduction of both groundwater extraction and desalination and a use of 35\% supply from treated domestic wastewater and a 5\% supply from treated industrial wastewater.

For sustainable water resources planning, we can use an MCDM approach for sustainable water management through incorporating possible water supply sources (groundwater, treated wastewater, surface and renewable water, and desalinated water), water demands (domestic, industrial, landscaping, and agricultural), cost, risk, social perception, and feasibility. A fuzzy multistage decision-making approach has already been developed for sustainable water resources planning (Chowdhury \& Husain, 2006).

\subsection{Future Strategy}

Sustainable water resources planning for the Kingdom of Saudi Arabia would use an MCDM methodology in developing an integrated water management plan at the regional and national levels (Figure 5). The proposed methodology would incorporate the conflicting objectives of such stakeholders as regulatory agencies, industries, and consumers in the decision-making process; possible qualitative and quantitative data on water supply sources, including groundwater, treated wastewater, surface and renewable water resources, and desalinated water; water demands for domestic, industrial, landscaping, and agricultural uses; and associated environmental and human health risks with each supply source.

A national plan on sustainable water resources planning should be formulated for the Kingdom which would help in developing coordination with water industries, consumers, the Ministry of Water and Electricity, the National Water Company, and regulatory agencies such as PME. In considering treated wastewater as an aquifer recharge and for landscaping and agricultural use, as a long-term alternative in the region, it is important to 
assess its impact on the environment and health and its economic and technological implications (Chowdhury \& Husain, 2006; Husain, 2009; Husain \& Ahmed, 1997).

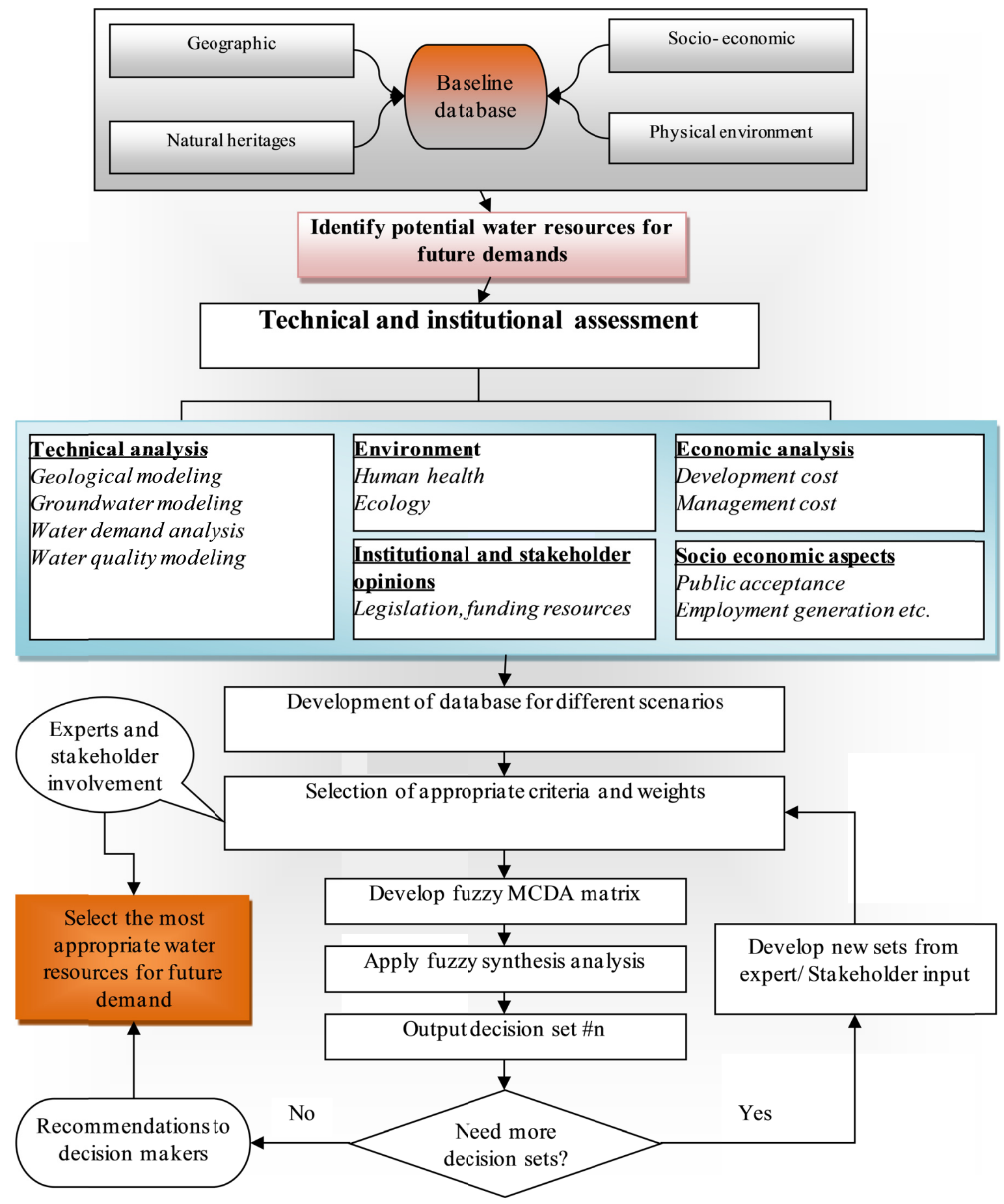

Figure 5. Water sustainability with interrelated components

The decision support model considers environmental, socio-economic, financial, and system reliability as criteria for evaluation. For environmental aspects, waste generation, the impact on marine and terrestrial ecosystems, flood management, climate-change impact, and public health issues are considered, while public acceptance, regional economic growth, job creation, and urban development are socio-economic indicators. System reliability criteria cover safe and reliable supply options to meet quality and quantity requirements. The cost of 
the system is another criterion in the development of each option and scenario. Figure 6 shows various attributes and indicators that need to be considered for both quantitative and qualitative data collection.

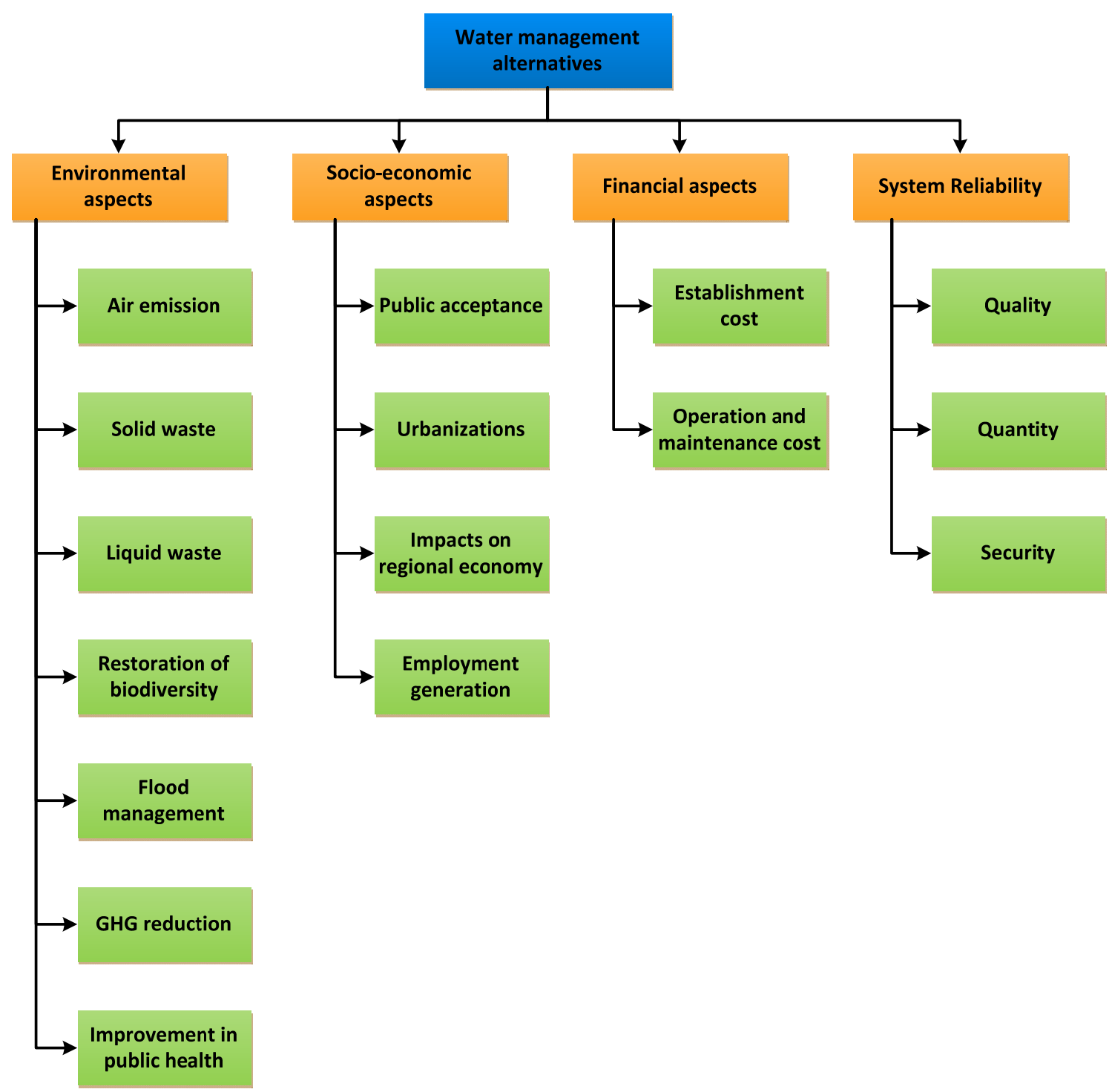

Figure 6. Sustainability indicators in evaluating water supply alternatives

The developed decision support model is designed to incorporate the opinions of different stakeholders such as regulatory agencies, industries, water industry experts, and consumers in the decision-making process. Stakeholders and end users should give their opinions of the four major water management attributes listed in Figure 6 and provide qualitative and quantitative inputs on various sub-attributes. This model is a powerful tool for informed decision-making and can be integrated with databases and other supporting software. The long-term impact of climate change on water resources is an important component and may adversely impact crop growth and terrestrial ecosystems, which will require the integration of conservation, wastewater use, and aquifer recharge to meet future demands.

An MCDM methodology considers both quantitative and qualitative inputs for decision-making purposes and analyzes the problem in the following sequences:

(1) Identification of alternatives

(2) Definition of basic attributes

(3) Defining ranking and weights for each attribute 
(4) Aggregation of attributes into generalized indicators

(5) Estimation and ranking of alternatives

Details on the above steps with their application to MCDM methodology can be found in Chowdhury \& Husain (2006), Mofarrah \& Husain (2010), Sadiq et al. (2003, 2004), and Sadiq \& Husain (2005). However, since environmental, engineering, and institutional participation in assessing alternatives are key to integrating sustainable water resources planning, qualitative and quantitative information should be collected and assessed for such planning, with the active participation of stakeholders from regulatory agencies, communities, municipalities, government, and private sector.

\section{Sustainable Energy Planning}

In Saudi Arabia, rapid population growth, industrialization, and urbanization put considerable stress on its existing energy supply systems. The demand for electricity is increasing by over $6 \%$ per year; this means that an additional $35 \mathrm{GW}$ of generating capacity will be needed by 2023 beyond the 2005 -installed capacity of $34.4 \mathrm{GW}$. As shown in Figure 7, crude oil and heavy fuel oil constitute about 50\% to generating this power.

\subsection{Current Status}

It is estimated that by 2050 energy demand in the Kingdom will be approximately $120 \mathrm{GW}$, and, to meet this growing demand, 8 million barrels of oil per day will be required. As a result, there will be no export of oil which will have a direct impact on the national economy. It is therefore important to develop a sustainable energy efficiency (EE) program by improving the efficiency of energy use and its generation and management in various industrial and residential sectors. Another option is to reduce the Kingdom's dependence on fossil fuel by developing renewable energy while simultaneously improving the efficiency of current and future energy resources. Clean and efficient uses of energy present an unprecedented opportunity to boost Saudi Arabia's prosperity. Billions of dollars can be saved by using energy more wisely and drawing on renewable energy sources. Burning fossil fuel could be a factor in numerous environmental problems. Traditional power plants produce air pollution and emit toxic chemicals and greenhouse gases into the atmosphere.

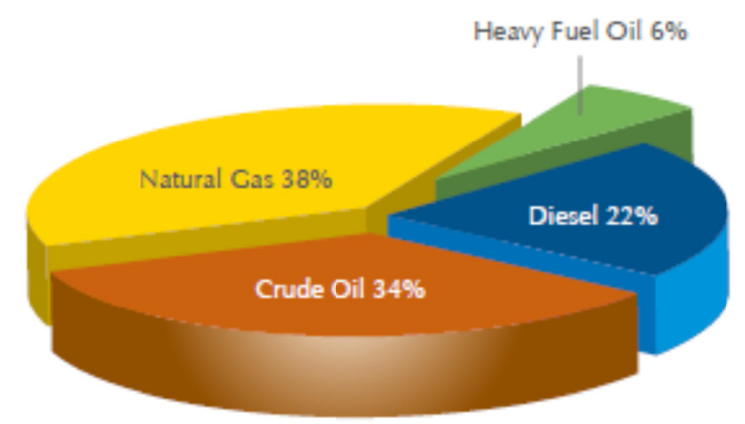

Figure 7. Fuel types used in electricity production in 2009 (ECRA, 2009)

Potential renewable energy sources for the Kingdom include solar and wind. The power from wind and solar radiation which reaches the earth is sufficient to make significant, strategic contributions to the Kingdom's energy supply (Shaahid \& Elhadidy, 1994). According to a study by Al-Ayed et al. (1998) on the city of Riyadh, the total solar radiation that occurred between May and August ranged from 7 to $8 \mathrm{kWhm}^{-2}$. Akram et al. (1995) found that solar radiation on a horizontal surface for Jeddah reached its highest value during June at 7.943 $\mathrm{kWhm}^{-2}$, with a beam (direct) component of $5.726 \mathrm{kWhm}^{-2}(72 \%)$ and a diffuse component of $2.119 \mathrm{kWhm}^{-2}$ (26\%). Alnaser et al. (2004) collected data from 208 stations in 19 Arab countries, including 46 stations in the Kingdom of Saudi Arabia, and produced a solar atlas of the region. Although data from 46 stations in such a vast country is insufficient, it however indicates that there is a significant potential of solar energy throughout the Kingdom. A solar map of Saudi Arabia was developed recently using data from 35 locations (Figure 8), and it identified potential areas for solar energy development within the Kingdom. 


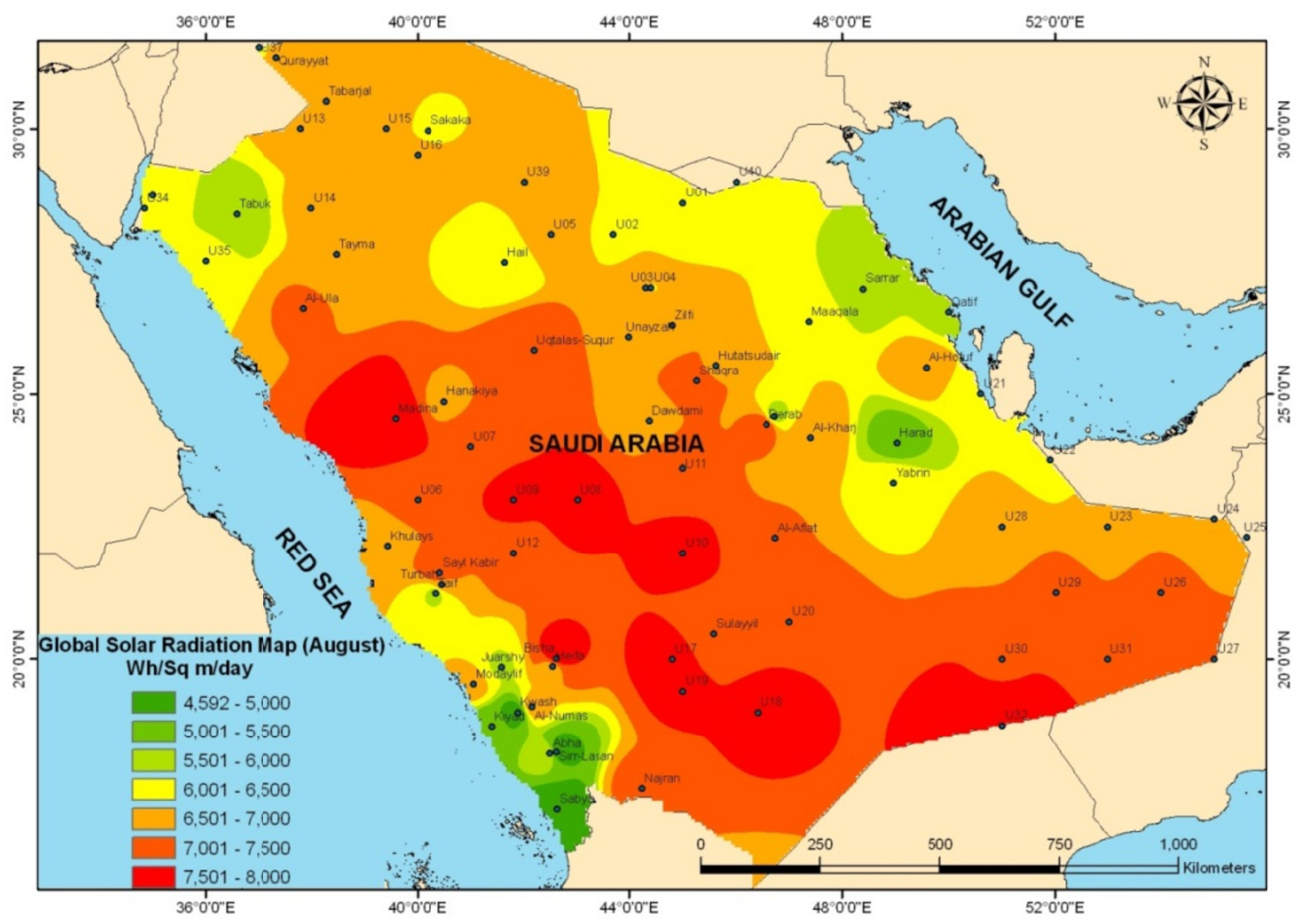

Figure 8. Daily direct normal radiation (Said et al., 2004)

A solar-energy-related study conducted in Saudi Arabia confirmed that the Kingdom has enormous solar-energy potential. Solar energy has a multitude of practical uses: lighting, cooling, water heating, crop/fruit drying, water desalination, operating irrigation pumps and meteorological stations, and in providing road and tunnel lighting, traffic lights, road instruction signals, as well as for small applications at remote sites (Alawaji, 2001). The effective practical utilization of solar energy needs reliable quantitative data on daily and annual distribution patterns of solar energy at given locations. It is essential not only for assessing the economic feasibility of solar energy utilization but also for design and environmental control.

Wind energy has gained attention as a possible alternative renewable energy source in Saudi Arabia. The mean annual wind speed exceeds 9 knots $(16.7 \mathrm{~km} / \mathrm{h})$ and ranges from about 14 to $22 \mathrm{~km} / \mathrm{h}$ and 16 to $19 \mathrm{~km} / \mathrm{h}$ over the Arabian Gulf and Red Sea coastal areas respectively (Magdy \& El-Samanoudy, 1985). According to Rahman (2004), Saudi Arabia is a vast open, flat land with moderate winds in general, and the city of Yanbu, which has an annual average wind speed of $4.6 \mathrm{~m} / \mathrm{s}$ at 10 meters above the ground surface, may be a candidate site for future wind-power generation. Al-Abbadi (2005) analyzed wind speed, direction, power density, and energy at five sites-Dhulum, Arar, Yanbu, Gassim, and Dhahran. This study revealed that these sites have the potential for wind energy development. Rahman (2004) assessed wind energy cost per kWh of electricity produced using three types of wind electric conversion systems at 20 locations. The hourly values of wind speed recorded for periods of 5.5-13 years were used for all 20 locations. This study confirmed that the average wind speed of the Kingdom lies in the moderate to high grade compared to the global average wind speed distribution at a 10 -meter height.

\subsection{Future Strategy}

Sustainable management of energy systems is a challenging task which involves a large number of social, economic, environmental, technical, and political factors. To deal with such complexities, appropriate strategies and tools are needed, including an optimization-based decision support tool for renewable energy assessment (DSTREA) (Figure 9). Such a tool will help in providing a comprehensive analysis of energy planning, climate change impacts, and energy and environmental policy responses within an energy management system framework. 
An MCDM method is integrated with mathematical models to incorporate institutional and legal boundary conditions as well as such socio-economic data as population, energy consumption, technology, land cover, road access, and the cost of a database of the region. DSTREA is an intelligent tool for analyzing and visualizing various scenarios within energy management systems, which can serve as a complete source of information for policy makers, advocates, landowners, developers, and others engaged in energy development and environmental management.

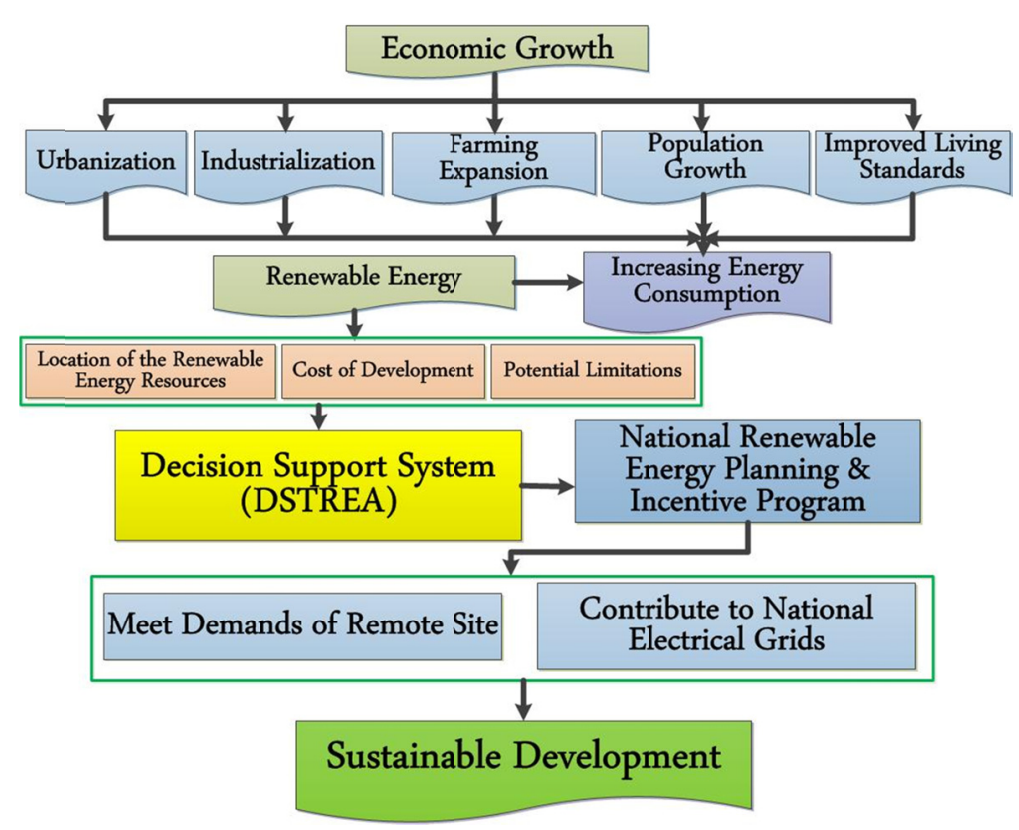

Figure 9. DSTREA and interconnected modules for sustainable energy planning

\section{Marine Pollution and Ecological Impact}

Saudi Arabia is surrounded by the Arabian Gulf on the east and the Red Sea on the west coast, and several cities and towns are located on these two coasts. The economy and living conditions of these coastal towns mainly depend on the status of its coastal ecosystem management and the protection of marine habitats.

\subsection{Current Status}

The Arabian Gulf has also been subjected to a wide range of human perturbations in the last 50 years due to unprecedented coastal reclamation and oil exploration, production, and transportation. The integrity of the Gulf's terrestrial ecosystem faces such challenges as a loss of biodiversity of fauna and flora, soil degradation, and sediment and nutrient loss. A sharp decline in marine species and overgrazing are challenges that need to be addressed. The stress on the Gulf's terrestrial ecosystem is further aggravated by the harsh environmental conditions facing many parts of the region.

With its high biological diversity, the Red Sea and the Gulf of Aden make up a unique ecosystem. The natural resources of both provide substantial economic support for the region. But continual degradation of the marine environment poses a threat to public health through contaminated seafood and polluted water. Damage to the marine ecosystem adversely affects the area's general attraction to tourists and it also has an adverse effect on the fishing industry.

The main sources of marine pollution in both of these coastal waters are land-based activities including urbanization and coastal development, industries including power and desalination plants and refineries, recreation and tourism, wastewater-treatment facilities, coastal mining and quarrying activities, oil bunkering, and such habitat modification as the dredging and filling of wetlands.

Much of the rapid expansion of urban centers has been achieved through an extensive use of desalinated water to meet the demands of the populace and industry. In terms of water issues, there are two areas of concern: the impact of thermal pollution on the marine ecosystem and elevated levels of salt and chlorine in the return waters. These impacts vary with water volume and discharge location (e.g., in shallow or deep water). Discharge from 
power and desalination plants can alter temperature and salinity, especially in semi-closed lagoons; mangrove mortality may be caused by a $3-5^{\circ} \mathrm{C}$ increase above ambient water temperatures in the tropics; and the diversity and mass of associated fauna may diminish by $90 \%$.

The discharge of partially treated or untreated municipal wastewater presents a significant management problem. In most cases, inadequate marine outfall systems discharge low-quality treated effluent into adjacent coastal waters. It is well known that excessive nutrient loads, especially phosphorus and nitrogen compounds, cause significant ecological changes. The structure of plankton communities is altered, with a preferential growth of small flagellates rather than the larger diatoms, and unusual plankton "blooms," uncontrolled by the normal processes of grazing.

Large recreational cities and centers have been developed along the Jeddah coastline in the absence of adequate planning or evaluation of potential environmental impacts. The construction of these large projects has required significant dredging and filling operations, which adversely impact coastal habitants.

\subsection{Future Strategy}

To restore safe environmental conditions and to preserve these water bodies, it is important that a marine ecological risk assessment methodology be developed and a scientifically sound systematic procedure for environmental impact studies for coastal zone management established for the Kingdom of Saudi Arabia. An Oil Spill Modeling Center should be established in coordination with PME and other regional marine organizations such as the Regional Organization of the Protection of Marine Environment (ROPME) and Protection of the Environment of the Red Sea and Gulf of Aden (PERSGA) in order to develop a sustainable plan to protect the marine environment in the region. Such integration would help in better understanding water-quality changes in coastal areas and in developing impact zones for accidental spills. The study would also help PME in coastal zone management and ecological risk assessment and management.

\section{Waste Management}

Millions of tons of waste are generated in the Kingdom every year from residential, commercial, and industrial sectors, but little attention is paid to its recycling, reuse, and reduction. Due to the improper disposal of these wastes, a growing concern is its ensuing threat to ecosystems and human health. It is difficult to categorize and discuss all wastes, but this paper's emphasis is on the waste generated from power plants and mineral processing, especially from phosphate- and bauxite-processing facilities.

\subsection{Current Status}

Burning fuel oil yields about $3 \mathrm{~kg}$ of ash per kiloliter of fuel oil (Tsai, S. L., \& Tsai, M. S., 1997) and most of this ash (approximately 90\%) passes through a flue gas stream and is collected by electrostatic precipitators (ESP) or cyclones (Hsieh \& Tsai, 2003). The fly ash generated by the burning of heavy fuel oil is generally termed heavy fuel oil fly ash (HOFA). On average, 50-60 tons of HOFA are generated per day from a mid-range (i.e., 2300 MW power generating capacity) power plant (Hsieh \& Tsai, 2003). Due to its local availability and relatively low cost, heavy fuel oil is used in most power generation facilities in Saudi Arabia: it uses about 320 million barrels of crude oil annually for power generation (Breakbulk online news, 2010-07-20), which produces about a quarter million tons of OFA, most of which is disposed of in landfills. HOFA is generated and disposed into the landfill. It is anticipated that the production of HOFA will continue to increase in the future. Therefore, power plants in the Kingdom may face difficulties with the disposal of the produced HOFA. Its current industrial management practices of HOFA mainly follow a dry disposal procedure, where the FA is transported by truck or conveyor from the power plant to the disposal site.

The Saudi Arabian Mining Company Ma'aden established a joint venture with Saudi Arabian Basic Industrial Corporation (SABIC) to build the world's largest integrated diammonium phosphate (DAP) fertilizer plant and bauxite/aluminum refining and smelter complex in Rasal Khair, on the Arabian Gulf coast, $90 \mathrm{~km}$ from the industrial city of Jubail. This plant is designed to produce 2.9 million tonnes of DAP per year (Mtpy) using 5 Mtpy of phosphate concentrate from Al-Jalamid. In the same industrial complex, RasAzZawr, an aluminum plant will be constructed and operated, including a 740,000 tonne per year (tpy) aluminum smelter and a 1.4 Mtpy alumina refinery. During the operation of these plants, a large quantity of phosphogypyum (PG) and red mud (RM) will be generated as waste residues. It is estimated that around 4-5 metric tons of PG for each ton of phosphate and 1-3 tons of RM sludge per ton of alumina will be produced, and stockpiled in a nearby area. Since these wastes contain organic and inorganic impurities, trace metals, and radioactive substances, its proper disposal and use is critical. 


\subsection{Future Strategy}

Potential economic incentive exists for developing innovative and environmental safe applications of OFA from power plants using heavy fuel oil. One study explored the sustainable potential use of HOFA as a natural adsorbent to remove organic and inorganic compounds from wastewater (Mofarrah et al., 2013a \& b; Mofarrah \& Husain, 2013). The preliminary results indicate that developed activated carbon from HOFA has potential industrial applications, especially removing heavy metals such as arsenic (As), copper $(\mathrm{Cu})$, and lead $(\mathrm{Pb})$ from wastewater streams. The results also indicate that developed activated carbon has the potential to remove $\mathrm{Cr}$ (VI) from wastewater. Under test conditions, a maximum of $91.51 \% \mathrm{Cr}$ (VI) removal efficiency was achieved. The study also showed that HOFA blended with cement can be used as soil stabilization material in an environmentally safe manner (Mofarrah et al., 2012a).

The extracted carbon from HOFA is useful in removing total organic carbon and disinfectant by-products (DBPs) from water supply systems (Ahmad, 2013; Ahmad et al., 2012; Husain et al., 2012). This research is an excellent example of sustainable waste management. From the Shoaibah and Rabigh power plants alone, about 80 tons of HOFA are collected and dumped into landfills every day. Since Saudi Arabia is currently installing large power plants in Khafji, South Jeddah, Shoaibah, and Rabigh with several GW capacity and all these plants will use heavy fuel oil, it is expected that the generation of HOFA will be several times higher than that being currently produced. Its proper management and disposal is therefore very critical in the future.

Phosphogypsum (PG) is primarily gypsum. Impurities include quartz, fluorides, phosphates, and organic matter, as well as $\mathrm{A} 1$ and $\mathrm{Fe}$ minerals, with elevated levels of trace elements such as $\mathrm{As}, \mathrm{Cd}, \mathrm{Cr}, \mathrm{Mn}, \mathrm{Pb}$, and ${ }^{238} \mathrm{U}$ decay products relative to background levels. It also includes residual acids (e.g., $\mathrm{H}_{2} \mathrm{SO}_{4}$ and $\mathrm{H}_{3} \mathrm{PO}_{4}$ ) and fluoride and sulfate anions. These trace elements, as well as major elements present, including sulfur (S), phosphorous (P), and fluorine (F), are of concern should they become mobilized from the PG and released into the environment. In addition, levels of $\mathrm{N}$ compounds, including $\mathrm{NO}_{3}$, which tend to be highly mobile, can be elevated in PG. Phosphate deposits around the world contain appreciable concentrations of radioactive material originating from the decay of $U$ and Th present in the ores. During processing, fractionation occurs, with most of the $U$ and Th dissolving through the acidulation of the phosphate rock with sulfuric acid, while most of the Ra is deposited with the PG. Thus, the main nuclides of concern in PG are ${ }^{226} \mathrm{Ra}$ and its daughter products. Groundwater contamination with radionuclides and atmospheric contamination with radon are potential hazards of PG stacks.

Red mud (RM) is highly alkaline, with a $\mathrm{pH}>11$. Due to its high alkalinity it can cause intense irritation. It also contains caustic soda, which can lead to air pollution and adverse health effects. The presence of trace elements such as arsenic in RM can pose human health hazards and environmental contamination in water and soils, if not disposed properly. It requires a proper handling and storage facility to minimize its adverse impacts on the environment. With a view to simultaneously protecting the environment and using these large amounts of waste by-product, such as construction material, soil treatment, or as a by-product to treat wastewater, etc., it is proposed that an in-depth investigation be conducted through laboratory and field experiments to identify their optimal use. Since RM is highly alkaline, with a high $\mathrm{pH}$, and $\mathrm{PG}$ has a lower $\mathrm{pH}$ value, their mixing in the right proportions may help in developing a stabilized product. However, such uses will require detailed scientific studies to better understand the mobility of various undesirable constituents present in both residues.

Since these two facilities are close to each other in the industrial complex of Rasal Khair, it will be a unique opportunity to identify the most cost-effective solution for their use. RM and PG, either as individual materials or as a mixture, can be considered as potential alternate construction materials, possibly in road embankment or in constructing coastal levees. The projected environmental benefit and cost savings of these secondary materials can be of considerable importance both environmentally and technologically. However, for the effective use of these residues, an appropriate level of assurance in the environmental performance and system design is crucial. PG can also be used as a substitute for natural gypsum after suitable treatment, and it can also be used as a cement binder in combination with other industrial by-products.

In the past, these residues, in combination with other materials, have been tested for use as adsorbents to remove heavy metals from waste streams, amendment of soil to increase crop yield by adding RM and PG in the sandy soil, and site remediation by reducing the mobility of heavy metals and other contaminants through soil stabilization. However, since both residues contain impurities in the form of heavy metals, radioactive materials, and other undesirable constituents, it is important to characterize these materials and conduct an in-depth investigation of their mobility, leaching, and impact through laboratory and field investigations before their recycling and reuse and testing for technology development. There is a vast amount of scientific literature available which will help in identifying and screening potential technology developments, but these results 
cannot directly be applied since the physical, chemical, and morphological characteristics of these residues are site-specific, with a significant variation in their characteristics. It is, therefore, necessary that a detailed characterization of ores and residue be carried out and the interaction and mobility of the contaminants present be scientifically studied before laboratory and field testing of the technology.

\section{Conclusions and Recommendations}

Sustainable development is a means to reconcile human development by safeguarding our future and improving the quality of life by resource conservation and protection of the environment and human health. This concept is promising, especially as the world is facing the many environmental challenges of global warming, desertification, air and water pollution, poverty, poor health, and loss of biodiversity. It emphasizes the importance of maintaining and improving the quality of life by ensuring that any decision made in this regard will integrate social, economic, and environmental consequences.

In the Kingdom of Saudi Arabia, remarkable progress is being made in implementing a sustainable development concept in government, industry, and businesses. Due to its population growth and an improved standard of living, the country has witnessed rapid economic development and industrialization, keeping a balance in economic growth, environmental protection, and social priorities. The tools and concept presented in this paper will help in economic development by protecting the environment and keeping the public and stakeholders involved in the decision- making process of finding alternate energy resources, managing waste, protecting water bodies, and developing alternatives for safe drinking water within a sustainable framework. Some of the key issues in the environmental discipline and long-term strategies to handle within a sustainable framework are as follows:

(1) Major cities show an elevated level of $\mathrm{NO}_{\mathrm{x}}, \mathrm{SO}_{2}$, VOCs, $\mathrm{O}_{3}$, and $\mathrm{PM}_{10}$. VOCs combined with high levels of $\mathrm{NO}_{\mathrm{x}}$ and sunlight are major contributors to $\mathrm{O}_{3}$ increase in urban areas. A sustainable national plan is therefore needed for air quality management and assessment through monitoring, modeling, and a risk assessment approach. Such a plan should keep a balance between sustainable economic development and the protection of human health and ecosystems with the active participation of stakeholders.

(2) Due to hot and arid climatic conditions and very little rainfall, fresh water in the Kingdom of Saudi Arabia is very limited. Population growth, an increase in the standard of living, and rapid economic development add stress on water availability in the region. A national plan on sustainable water resources planning should therefore be developed with an emphasis on water conservation and the use of treated wastewater for aquifer recharge, landscaping, and restricted agricultural use. It is also important to assess its impact on the environment and health and its economic and technological implications. This national plan should also integrate possible water supply sources (groundwater, treated wastewater, surface and renewable water, and desalinated water), water demands (domestic, industrial, landscaping, and agricultural), and their associated cost, risk, and social perception using an MCDM methodology.

(3) The energy demand in the Kingdom will be approximately $120 \mathrm{GW}$ by 2050 . To meet this growing demand, 8 million barrels of oil per day will be used in power utility systems. As a result, there will be no export of oil which will adversely impact national economy. It is therefore important to develop a sustainable energy efficiency (EE) program by improving the efficiency of energy use and its generation. Another option is to reduce the Kingdom's dependence on fossil fuel by developing renewable energy while simultaneously improving the efficiency of current and future energy resources. Since the Kingdom has enormous solar and wind energy potential, appropriate strategies and tools are needed, including an optimization-based decision support tool to help in providing a comprehensive analysis of energy planning, climate change impacts, and energy and environmental policy responses within an energy management system framework.

(3) Saudi Arabia is surrounded by the Arabian Gulf on the east and the Red Sea on the west coast. Several cities and towns are located on these two coasts and their economy and living conditions depend on the status of the coastal ecosystem and the protection of marine habitats. These coastal regions have been subjected to a wide range of human activities, with a loss of biodiversity, soil degradation, and sediment erosion. To restore these water bodies, it is important that a marine ecological risk assessment methodology be developed and a scientifically sound systematic procedure for coastal zone management established for the Kingdom of Saudi Arabia. An Oil Spill Modeling Center should be established in coordination with PME, ROPME, and PERSGA.

(4) Millions of tons of waste are generated every year, most of which are either dumped into landfills or piled near industrial facilities, and cause environmental threat and economic loss. In order to sustain development and protect the environment, an integrated concept on waste reduction, recovery of usable materials, and recycling and reuse of waste should be developed. 


\section{Acknowledgement}

The support provided by the Natural Sciences and Engineering Research Council (NSERC) of Canada is greatly appreciated.

\section{References}

Ahmad, M. (2013). Affordable filtration technology of safe drinking water for rural Newfoundland. M. Eng. Thesis, Memorial University of Newfoundland, St. John's, Canada.

Ahmad, M., Mofarrah, A., \& Husain, T. (2012). Development of cost-effective filtration technology to remove disinfectant by-products for drinking water supply system. The First Saudi International Environmental Technology Conference, KACST, Riyadh, Saudi Arabia, May 13-15, 2012.

Akram, A., Zuhairy, \& Sayigh, A. A. M. (1995). Simulation and modeling of solar radiation. Saudi Arabia Renewable Energy, 6(2), 107-118. http://dx.doi.org/10.1016/0960-1481(94)00056-C

Al-Abbadi, N. M. (2005). Wind energy resource assessment for five locations in Saudi Arabia. Renewable Energy, 30, 1489-1499. http://dx.doi.org/10.1016/j.renene.2004.11.013

Al-Ayed, M. S., Al-Dhafiri, A. M., \& Bin Mahfoodh, M. (1998). Global, direct and diffuse solar irradiance in $\begin{array}{llll}\text { Riyadh. Saudi Arabia. } & \text { Renewable Energy, }\end{array}$ http://dx.doi.org/10.1016/j.apenergy.2009.06.032

Al-Humoud, J. M., Behbehani, H. M., \& Abdullah, T. H. (2003). Wastewater reuse practices in Kuwait. The Environmentalist, 23, 117-126. http://dx.doi.org/10.1023/A:1024831503569

Alawaji, S. H. (2001). Evaluation of Solar Energy Research and its Applications in Saudi Arabia-20 Years of $\begin{array}{lllll}\text { Experience. Renewable and Sustainable Energy Reviews, 5, } & \text { 59-77. }\end{array}$ http://dx.doi.org/10.1016/S1364-0321(00)00006-X

Alnaser, W. E., Eliagoubi, B., Al-Kalak, A., Trabelsi, H., Al-Maalej, M., El-Sayed, H. M., \& Alloush, M. (2004). First solar radiation atlas for the Arab world. Renewable Energy, 29, 1085-1107. http://dx.doi.org/10.1016/j.renene.2003.10.007

Chowdhury, S., \& Husain, T. (2006). Evaluation of drinking water treatment technology: An entropy-based fuzzy application. Journal of Environmental Engineering, ASCE, 132(10), 1264-1271.

ECRA (Electricity Cogeneration and Regulatory Authority). (2009). Annual Report, Kingdom of Saudi Arabia.

Hsieh Y.-M., \& Tsai, M.-S. (2003). Physical and chemical analyses of unburned carbon from oil-fired fly ash. Carbon, 41, 2317-2324. http://dx.doi.org/10.1016/S0008-6223(03)00283-5

Husain, T. (2009). Integration of wastewater reuse in sustainable water resources planning in arid regions. Journal of Applied Global Research, 2(1), 23-37.

Husain, T., \& Ahmed, A. H. (1997). Environmental and economic aspects of wastewater reuse in Saudi Arabia. Water International, 22, 108-112. http://dx.doi.org/10.1080/02508069708686680

Husain, T., Ahmad, M., \& Mofarrah, A. (2012). 15th Canadian Drinking Water Conference, Nov. 21-23, Kelowna, $\mathrm{BC}$, Canada.

Husain, T., Mofarrah, A., \& Danish, E. Y. (2010). Recent progress and future directions for air quality management in Saudi Arabia. Journal of International Business Management\& Research (JIBMR), 1(2).

Magdy, I. Amin, \& El-Samanoudy, M. (1985). Feasibility study of wind energy utilization in Saudi Arabia. Journal of Wind Energy and Industrial Aerodynamics, 18(2), 153-163. http://dx.doi.org/10.1016/0167-6105(85)90094-7

Mofarrah, A., \& Husain, T. (2010). A holistic approach for optimal design of air quality monitoring network expansion in an urban area. Atmospheric Environment, 44(3), 432-440. http://dx.doi.org/10.1016/j.atmosenv.2009.07.045

Mofarrah, A., \& Husain, T. (2011). Multi-criteria decision making for sustainable water resources management, 64th CWRA National Conference, June 27-30, St. John's, NL, Canada.

Mofarrah, A., \& Husain, T. (2013). Evaluation of environmental pollution and possible management options of heavy oil fly ash. Journal of Material Cycles and Waste Management, 15, 73-81. http://dx.doi.org/10.1007/s10163-012-0090-9 
Mofarrah, A., Husain, T., \& Al-Harbi, B. (2011). Design of urban air quality monitoring network: Fuzzy based multi-criteria decision making approach. In Nicolas Mazzeo (Ed.), Air Quality Monitoring, Assessment and Management (pp. 25-40). InTech. ISBN 978-953-307-317-0. http://dx.doi.org/10.5772/16716

Mofarrah, A., Husain, T., \& Bottaro, C. (2013a). Characterization of activated carbon obtained from Saudi Arabian fly ash. Int. Journal of Environmental Science and Technology (IJEST) (under review). http://dx.doi.org/10.1007/s13762-013-0370-5

Mofarrah, A., Husain, T., \& Chen, B. (2013b). Response surface methodology for optimizing Cr (VI) adsorption on activated carbon produced from heavy oil fly ash. Journal of Material Cycles and Waste Management (accepted).

Mofarrah, A., Husain, T., \& Danish, E. Y. (2012a). Investigation of the potential use of heavy oil fly ash as stabilized fill material for construction. J. Mater. Civil Eng. ASCE, 24(6), 684-690. Permalink: http://dx.doi.org/10.1061/(ASCE)MT.1943-5533.0000442

Mofarrah, A., Husain, T., \& Danish, E. Y. (2012b). Communicating human health risks associated with airborne particulate released from fly ash dumping site: Probabilistic approach, book chapter AcademyPublish.org Risk Assessment and Management (pp. 356-367). ISBN: 978-0-9835850-0-8. http://www.academypublish.org/papers/pdf/331.pdf

Rahman, S. (2004). Wind energy resources assessment for Yanbu, Saudi Arabia. Energy Conversion and Management, 45, 2019-2032. http://dx.doi.org/10.1016/j.enconman.2003.11.009

Sadiq, R., \& Husain, T. (2005). A fuzzy-based methodology for an aggregative environmental risk assessment: A case study of drilling waste. Environmental Modeling and Software, 20(1), 33-46. http://dx.doi.org/10.1016/j.envsoft.2003.12.007

Sadiq, R., Husain, T., Veitch, B., \& Bose, N. (2003). Risk management of drilling waste disposal in the marine environment-a holistic approach. Oceanic Engineering International, 17(1), 1-22.

Sadiq, R., Husain, T., Veitch, B., \& Bose, N. (2004). Risk-based decision-making for drilling waste discharges using fuzzy synthetic evaluation technique. Ocean Engineering, 31(16), 1929-1953. http://dx.doi.org/10.1016/j.oceaneng.2004.05.00

Said, S. A. M., El-Amin, I. M., \& Al-Shehri, A. M. (2004). Renewable energy potentials in Saudi Arabia. Beirut Regional Collaboration Workshop on Energy Efficiency and Renewable Energy Technology, American University of Beirut. April 2004. 76-82.

Shaahid, S. M., \& Elhadidy, M. A. (1994). Wind and solar energy at Dhahran, Saudi Arabia. Renewable Energy, 4(4), 441-445. http://dx.doi.org/10.1016/0960-1481(94)90052-3

Shareef, M. M., Al-Zahrani, M. A., \& Al-Layla, R. (2005). Multi-objective water resources planning with uncertainties: Model development and application. Research Institute, King Fahd University of Petroleum \& Minerals. Dhahran, 31261, Saudi Arabia, 2005.

Tsai, S. L., \& Tsai, M. S. (1997). Study on the physical and chemical characteristics, yield and TCLP test of oil-fired fly ash. Mining Metallurgy, 41(2), 57-68.

\section{Copyrights}

Copyright for this article is retained by the author(s), with first publication rights granted to the journal.

This is an open-access article distributed under the terms and conditions of the Creative Commons Attribution license (http://creativecommons.org/licenses/by/3.0/). 